\title{
SMART SERVICES TO CREATE AN ESDI FROM NSDI: THE EUROPEAN CHALLENGE
}

\author{
Andreas Illert \\ Bundesamt für Kartographie und Geodäsie, Frankfurt am Main, Germany - andreas.illert@bkg.bund.de
}

KEY WORDS: Databases, Integration, Federated, Infrastructure, Standards, Model

\begin{abstract}
:
The environmental sector in the European Union has taken the lead in an initiative called INSPIRE that aims at creating the framework for the European Spatial Data Infrastructure (ESDI). With INSPIRE it shall be possible to combine spatial data from different sources in the National Spatial Data Infrastructures (NSDI) across the Community in a consistent way and share them between several users and applications. INSPIRE legislation is legally binding on all authorities in the EU member states. From a technical point of view, INSPIRE shall achieve the interoperability of spatial data sets by means of network services. The client of such services shall be enabled to discover, view and download spatial data sets in conformance with harmonised European specifications. INSPIRE promotes conceptual modeling and mandates formal modeling languages such as UML and GML. The domain experts need to find a balance between advanced concepts and traditional but well established patterns, while the proposed solutions should not result in excessive costs for the data providers.
\end{abstract}

\section{INTRODUCTION}

In Europe the users of spatial data benefit from an abundant supply of data sets and services. But at the same time they suffer from the variety in data formats and semantic models. For historical and organisational reasons the political division of Europe is superimposed on the offering of spatial data sets. It may not come as a surprise that the environmental sector is among the first groups of users to complain on the lack of cross-border data, as environmental threats do definitely not stop at the borders. Recognising the demand for getting access to data from the Member States in a simple and homogeneous way, the Environment Directorate-General of the European Commission has taken the lead in an initiative called INSPIRE, the acronym for Infrastructure for Spatial Information in Europe.

INSPIRE aims at creating the framework for the European Spatial Data Infrastructure (ESDI). With INSPIRE it shall be possible to combine spatial data from different sources across the Community in a consistent way and share them between several users and applications. Following the statutes of the European Commission, that ESDI shall obey to the principles of subsidiary, i.e. data should be kept where it is and to provide access to it.

INSPIRE is built on a legal framework, comprising a European Directive, the corresponding national laws, Implementing rules and associated guidance documents. That legal framework defines the responsibilities and technical parameters for setting up a service-oriented architecture. When developing the regulations, the experts in the INSPIRE drafting teams find that they provide smart solutions while they reveal new challenges at the same time. This paper describes the current stage in INSPIRE and highlights some of the challenges, with focus on the harmonisation of semantic models.

\section{THE LEGAL FRAMEWORK}

\subsection{The Directive}

With the European Commission being the driving force, the INSPIRE initiative uses the tools that the Commission has at hand when dealing with the Member States. These are - in first place - the legal measures. The central piece in INSPIRE is a Directive, i.e. a a legislative act of the European Union that is binding to the member states as to the result to be achieved, but leave to the national authorities some choice in implementation. The INSPIRE Directive (European Parliament and Council, 2007) has been drafted by the Commission, then discussed and adopted by the European Parliament and the Council. The Directive entered into force on 15 May 2007. Member States were required to transpose the Directive into national law within two years from that date. By the time of this article, all Member States have established such laws (De Groof, 2011). Many national laws do not only transpose the European Directive but define the framework for the national and regional SDIs as well.

The European Commission recognizes the efforts by the Member States. As a principle INSPIRE shall build upon infrastructures for spatial information established and operated by the Member States. Data should be collected only once and kept where it can be maintained most effectively. The European Commission requires the authorities to share their spatial data with other users and applications at any level, to make possible to combine seamless spatial information from different sources across Europe, and to publish information on the content of data and the conditions for use.

Further to defining the goals, the European Commission outlines the technical procedures for implementation. The directive requires the data providers to implement network services 
that enable the users to discover, view and download spatial data sets in conformance with harmonised European specifications. To achieve the interoperability of spatial data sets, the Directive demands for:

$>$ discovery services making it possible to search for spatial data sets and services on the basis of the content of the corresponding metadata;

$>$ viewing services making it possible to display, navigate, zoom in/out, pan, or overlay viewable spatial data sets; and

$>$ Download services enabling copies of spatial data sets, or parts of such sets, to be downloaded and, where practicable, accessed directly.

Subject to INSPIRE are data sets that meet the following conditions:

D they are held by or on behalf of a public authority,

$>$ they are in electronic format

$>$ they relate to an area where a Member State has and/or exercises jurisdictional rights

$>$ they relate to one or more of the themes listed in Annex I, II or III. The themes are very broad and cover almost every aspect of spatial data, from general reference data to domain data e.g. geology and meteorology.

The Commission does not reimburse the Members States for their efforts in implementing INSPIRE. Therefore, the effect on budget needs to be limited. The European Commission explicitly states that the Directive should not set requirements for the collection of new data. Moreover, the Implementing rules should not result in excessive costs for Member States.

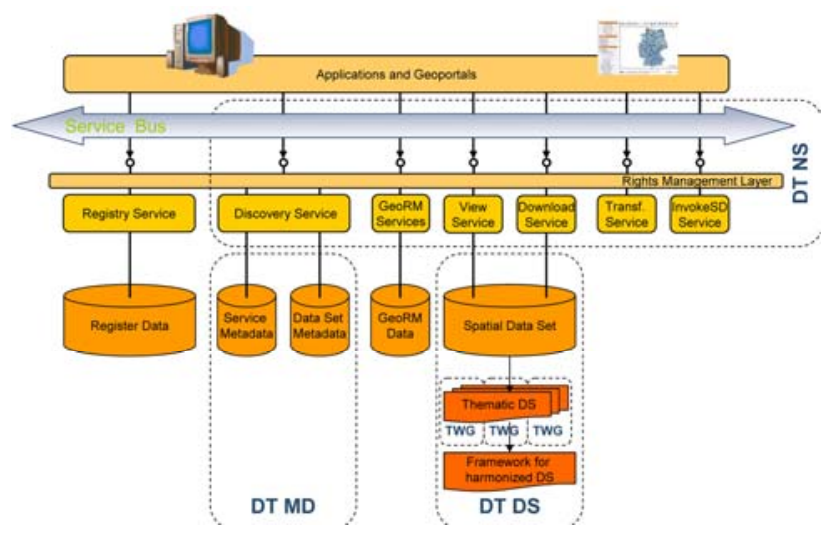

Figure 1. INSPIRE Architecture overview (European Commission Joint Research Centre, 2007)

\subsection{The Implementing Rules}

To ensure that the spatial data infrastructures of the Member States are compatible, the Directive calls for common Implementing Rules in a number of specific areas (Metadata, Data Specifications, Network Services, Data and Service Sharing and Monitoring and Reporting). These Implementing Rules are adopted as Commission Regulations. The Commission is assisted in the process of adopting such rules by a regulatory committee composed of representatives of the Member States.
The Regulations are legally binding on all authorities in the EU Member states. The Implementing Rules do not need to be transposed into national legislation. The target dates for adoption of the Implementing Rules and the deadline for Members states to fully implement the regulations are set by the Directive. Implementing Rules should be based, where possible, on international standards. In addition to the Implementing Rules, non-binding Technical Guidance documents describe detailed implementation aspects and provide examples and best practice.

\section{THE SERVICE-ORIENTED ARCHITECTURE}

\subsection{Metadata and Discovery Service}

Discovery services and the underlying regulation on metadata are most advanced in the process. The metadata regulation (European Commission, 2008) has been the first Implementing Rule being adopted by the INSPIRE Committee already in 2008 . It covers metadata for spatial data sets as well as metadata for spatial services. The regulation defines a list of metadata elements, their multiplicity and conditions. The list has been designed very close to the international standards ISO 19115 and ISO 19139, but the mandatory core metadata of INSPIRE does not exactly coincide with the respective requirements from the ISO standards. For instance, the INSPIRE Directive mandates data providers to publish information on limitations on public access, which has been added as a mandatory metadata element to the INSPIRE list. A mapping between INSPIRE metadata elements and ISO 19115/19119 is elaborated by the European Commission as a non-binding guidance document (European Commission Joint Research Centre, 2009).

INSPIRE metadata is published by means of INSPIRE Discovery Services. The Implementing Rules on discovery services (European Commission, 2009) were adopted in 2009 under the regulation on Network Services. This regulation defines the operations of the service, the parameters of the operations, the minimum search criteria and the corresponding metadata elements. Furthermore the regulation establishes minimum quality criteria relating to performance, capacity and availability of the service.

Discovery services constitute an essential component in the publish-find-find paradigm. By means of the services the data provider publishes the metadata on his data sets. The user searches the metadata, finds the data of interest including the URI for access, and binds the service into his application.

With INSPIRE being designed to link national spatial data infrastructures, the network services offer some specific capabilities. The federated search is such a feature. The Discovery Service may accept a request from a client and distribute the request to other Discovery Services within a federation. In this case a Discovery Service acts as both a server and as a client for another Discovery Service (European Commission Joint Research Centre, 2009), (figure 2).

The Regulation requires the Member States to provide Discovery Services with full functionality but without guaranteeing the quality of service not later than 9 May 2011. Half a year later - by 9 November 2011 - the data providers 
must fulfill the minimum quality criteria in conformity with the regulation.

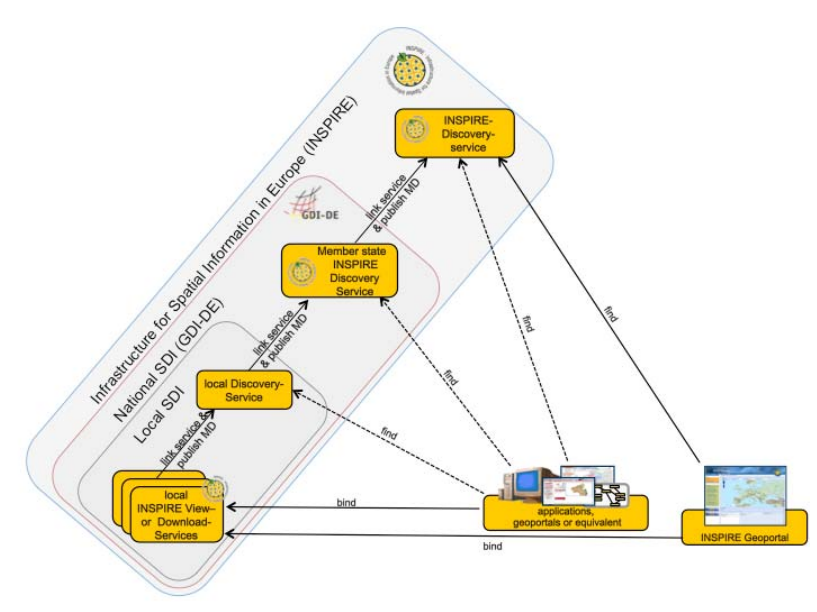

Figure 2. Example for linked discovery services in Germany (European Commission Joint Research Centre, 2009)

\subsection{View Service}

INSPIRE View Services allow users and computer programs to view spatial datasets. Likewise the regulation on Discovery Services, the regulation on View Services (European Commission, 2009) defines the operations of the service, the parameters of the operations and the minimum quality criteria relating to performance, capacity and availability of the service.

The layers shall be simultaneously viewed using a single coordinate reference system. The View Service shall support at least the ETRS89. With respect to data formats, The View Service shall support at least the Portable Network Graphics (PNG) format or the Graphics Interchange Format (GIF). The INSPIRE view service is designed very close to the ISO 19128 / OGC WMS standard. INSPIRE extensions to the OGC WMS include the handling multilingual aspects and measures that allow the linking of view services together.

The target dates for the implementation of View Services coincide with the target dates for the Discovery Services.

\subsection{Download Service}

The Regulation on Download Services (European Commission, 2010b) distinguishes two main types - download services for pre-defined data sets or pre-defined parts of data sets, and direct access download services including a query capability.

The first type is similar to a simple file-based download. The client downloads the data set as a complete unity with no possibility to change its content. The metadata contains a URL whereby the data set can be immediately downloaded by a simple HTTP-protocol GET-request. Unless the specifications for the individual data themes specify in a different way, the pre-defined data shall be encoded in GML.

The second type - 'Direct Access Download' - provides access to the spatial objects in the data set and is based upon a query. The client application interacts directly with a repository, e.g. a database. The INSPIRE download service for direct access is based on the OGC Web feature service, WFS, as specified in ISO/DIS 19142, and its query facility is based on the Filter encoding, FE, as specified in ISO/DIS 19143.

The Regulation requires the Member States to provide Download Services with full functionality but without guaranteeing the quality of service not later than 28 June 2012. Half a year later - by 28 December 2012 - the services must be fully conformant.

\subsection{Interoperability of data sets and services}

A key issue for INSPIRE is the cross-border compliance of semantic models. Harmonized semantic models are required for the definition of layers with the View Services as well as for the definition of data models with the Download Services. For that purpose, data specifications (European Commission Joint Research Centre, 2011a) are developed for each of the 34 Annex themes.

A data specification shall cover the definition and classification of spatial objects relevant to spatial data sets and the way in which those spatial data are geo-referenced. For the usage with network services the model should be readable by machines. Therefore, the INSPIRE teams decided to develop and maintain the semantic models in UML. A GML application schema and the feature catalogue in natural text are derived from the UML repository with automated tools.

Further to the conceptual model of the theme, the INSPIRE data specifications provide recommendations and requirements on data quality, define theme-specific extension for the metadata, introduce theme-specific deviations from the default data transfer format and the coordinate reference system if necessary, and describe the layers for the view service.

It should be emphasized that the data specifications do not mandate the way how spatial data is captured and maintained at the authorities in the Members States. INSPIRE only introduces yet another way how the data is published. In most cases the INSPIRE Services and the INSPIRE semantic model will be implemented in addition to the already existing national and/or domain-specific options. Data providers typically transform the data from their core database into the INSPIRE model either on the fly or via a secondary database, and run the INSPIRE network services on that secondary database.

Taking into account the priority in implementation on the one hand and the different requirements to reference and thematic data on the other hand, INSPIRE has grouped the themes into three Annexes. For themes from Annexes I and II the Directive requires a more comprehensive approach to harmonisation then for Annex III. For Annex I the Directive sets earlier deadlines then for Annex II and III. By now the data specifications for the nine themes of Annex I are already adopted as a regulation (European Commission, 2010a and 2011a.). The Member States shall enable for viewing and downloading in conformance with the specifications by the year 2017 at latest (European Commission Joint Research Centre, 2011b).

The data specifications for the 25 themes under Annex II and III - including orthoimagery and digital elevation models - are currently under development. If the process proceeds to schedule the data specifications will be adopted under the regulation on interoperability by the end of 2012, and Member 
States will be required to provide services in conformance with the INSPIRE models by the year 2019 .

The advanced techniques in conceptual modeling need to be justified with cost-benefit considerations and transposed into legal documents. The domain experts need to find a balance between flexible but generic models and the traditional feature classification patterns which are less flexible but easy to use. Some of the challenges in harmonisation of semantic models will be explained in the following.

\section{CHALLENGES IN HARMONISATION}

\subsection{Laws or standards?}

With INSPIRE being established by means of laws and regulations, the authorities of the Member States cannot escape the task of cross-border harmonisation. On the positive side, the law provides good arguments for them for asking their native government for extra funding and staff. Looking across Europe one can recognize that INSPIRE legislation has given the National Spatial Data Infrastructures a boost, and it is not only the cross-border affairs that benefit from it.

The INSPIRE Directive clearly advices the drafting teams to build the regulations on international standards, where possible. This includes domain standards e.g. from IHO and WMO, but even more the generic standards in Geographic Information as established by ISO, CEN and OGC. In fact the standards such as GML, WMS, WFS and WCS constitute the core of the service-based architecture as defined by the INSPIRE regulations.

However, the INSPIRE drafting teams had to learn that legal documents may not formally refer to standards from OGC and ISO (unless approved by CEN) as the procedures for adoption of such standards do not comply with the requirements for adoption of laws and regulations under the terms of the European Commission. In consequence, the regulations do not simply reference the standards but copy some of the content, e.g. for the operations of the WFS and WMS. The relationship with the standards is described in the guidance documents. With this measure, the INSPIRE regulations are consistent with the standards at the time of adoption. However, it is not guaranteed that they remain consistent, as modifications and improvements to the standards may not be introduced to the regulations without major delays.

\subsection{Interoperability versus "full" harmonisation}

Harmonisation of data sets is a very demanding task. One can split it into individual steps, with increasing complexity:

The first step comprises transformation into a common coordinate system and a common data format, at least for the exchange of data. This "syntactical harmonisation" is sufficient for the display of data from multiple sources by overlay on a computer screen.

Next to syntactical harmonisation comes semantic harmonisation. The data sets are transformed into a common semantic model. All data sets follow the same classification into feature types and feature attributes. This is what INSPIRE mandates, under the term of "interoperability". The data sets can be used together in a single application.
Mapping two data sets that cover the same area or adjacent areas into a common semantic model does not mean that instances of individual objects within the classes become the same. For example, a natural watercourse might be associated with the feature type "river" in both datasets, but one dataset combines the whole river into one spatial object, while the other dataset splits the river into segments and handles each segment as a separate spatial object. In order to harmonise data sets at the object level, one need common rules for the definition of instances of feature types. Such rules are out of scope for INSPIRE. It is left to the other European legislation, to domainspecific standardisation or to the Member States to introduce such rules for their era of responsibility.

The ultimate step in harmonisation is merging the data sets into one, which means that two or more individual representations of the same real world object are not only identified and linked by a unique ID, but merged into a single geometry holding the attributes from all source datasets. The result would constitute the ideal reference data: a single geometry where all thematic data can be referenced to. But this would require a lot of reengineering, and it would change the responsibilities in data capture and maintenance. Therefore, INSPIRE mandates syntactical harmonisation and semantic harmonisation, but does not go beyond this level with its requirements to Member States.

\subsection{Well established techniques versus advanced concepts}

Traditionally the content of a data product is defined in terms of semantics by means of a feature catalogue or a feature concept dictionary. Such catalogues and dictionaries are presented in a natural, human readable language. The approach with INSPIRE data specifications is somewhat different. INSPIRE mandates a conceptual model in a formal modeling language, namely UML, in compliance with ISO 19103 Geographic Information Conceptual schema language. Such a schema is machine readable, thus allowing for automated conformance check and possibly - for schema translation by automatic tools. With UML the common parts of the thematic models can be extracted quite easily and maintained in separate cross-theme packages. Vice versa, the UML schemas from ISO can be imported and re-used.

For inclusion to the specifications, a graphic overview and a feature catalogue is derived automatically from the UML schema. The feature catalogue still carries typical characteristics of a UML schema, such as relationship between classes by inheritance. It is quite hard for a reader who is not familiar with the principles of UML to obtain and understand the necessary information from the packages and subtypes. For example, you may need to analyse the cardinality of an association to find out if a feature is mandatory or optional. When talking to domain experts who have no in-depth knowledge of formal modeling, it turns out that many of them do not fully understand the INSPIRE data specifications. The approach chosen by INSPIRE (and ISO) is still at the edge of technology. There is quite a danger that technicians who do not understand the models may refuse to adhere to INSPIRE at all.

\subsection{Predefined classification versus generic approach}

The Thematic Working groups (TWGs) in charge of the data specifications have to comply with expectations that are not easy to combine in a single result. They shall develop a harmonised conceptual model for their domain where all national models and the existing international classification systems can be mapped to. Implementation of that mapping 
should not put excessive costs on the data providers. At the same time the model should meet the needs of users, yet not specified exactly who and how but generally described as "policies and activities that may have a direct or indirect impact on the environment" (European Parliament and Council, 2007)

The challenge gets obvious at the example of the spatial data theme "land cover". A number of predefined classification systems already exist in Europe, for example CORINE. The TWGs shall consider them, but at the same time they are asked to not prioritize one above the other unless for very good reasons. Such reasons are not at hand, as each system meets its purpose, and dropping all but one would mean excessive costs not only for the custodians of the neglected systems but also for users who need to re-engineer their applications. Therefore the TWG decided to propose a generic model (INSPIRE Thematic Working Group Land Cover, 2011). They do not mandate a single codelist for classification but allow the data provider to keep the semantics in the original system. Harmonisation is introduced by requesting the data provider to document his classification system in a systematic manner (figure 3). Thus the specification is flexible and open. However, the burden of harmonisation is shifted to the user, who is provided with information on the semantics but may need to do perform a transformation to the target system on his own.

Almost every spatial data theme was confronted with that type of challenge in the one or other way. When studying the specifications you will notice that the solutions differ, depending on the decision of the respective TWG what they consider a reasonable balance between harmonisation and flexibility.

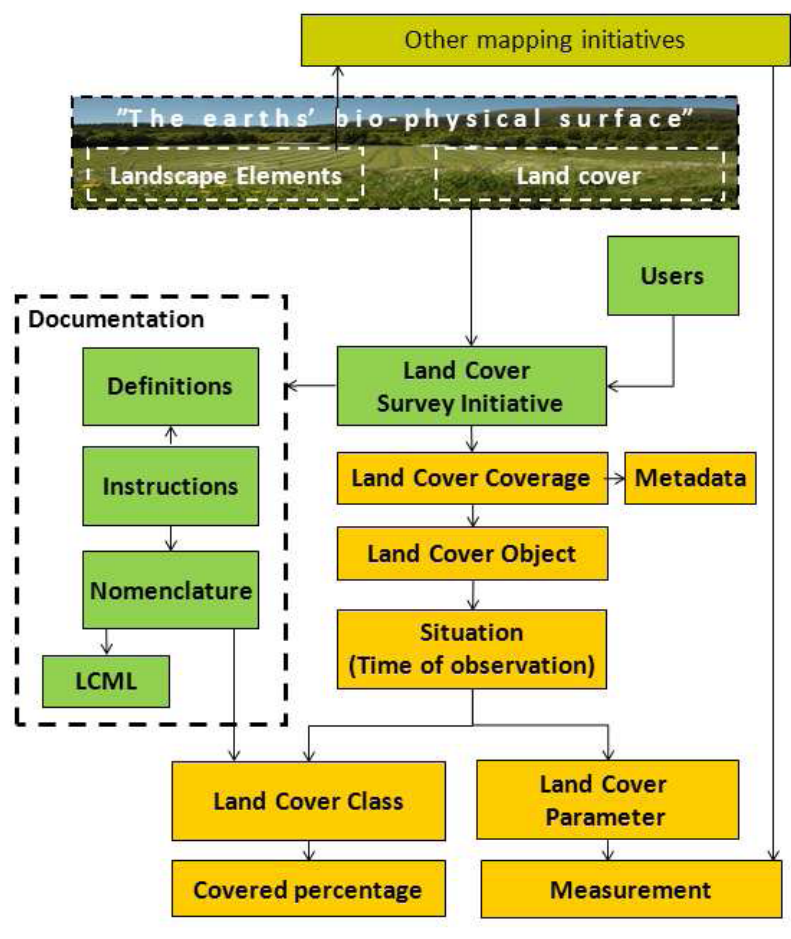

Figure 3. An informal rendition of the complete INSPIRE land cover data model (INSPIRE Thematic Working Group Land Cover, 2011)

\subsection{Development of semantic model top down or bottom up}

At the very beginning of the drafting process for the data specifications, the responsible experts needed to decide on the methodology. On the one hand, INSPIRE demands for consistency between the spatial data themes. That requirement would be met best with a top down approach, starting from modeling the real would at a very general level, then refining it for the individual domains resp. spatial data themes. On the other hand, it was obvious that the variety of INSPIRE themes (ranging from postal addresses to atmospheric conditions) will not easily fit under a single umbrella, that combining ISO 19100 and existing domain standards would call for compromises, and that the INSPIRE schedule was too tight to allow for optimisation loops between the general level and the fine level.

The actual methodology is a compromise. The focus is clearly on the level of spatial data themes. The major part of work rests on the shoulders of the domain experts. To tie the themes together, a Generic Conceptual Model (INSPIRE Drafting Team Data Specifications, 2010) defines the common rules for modeling and holds the generic parts of the thematic models such as OGC simple features, identifier management and multilingual text. If it is discovered during the development of theme specifications that a pattern is common to two or more themes, that pattern is raised to the level of the Generic Conceptual Model.

\section{ACTORS AND ROLES}

The European Commission was and is the driving force behind the initiative. They are the most prominent customer for crossborder data and services, but they are not the only one. Yet the Commission has not decided in detail on their role in maintenance and funding of an ESDI in operation.

The National Spatial Data Infrastructures got a big boost from INSPIRE. Their involvement in the ESDI affairs by providing expertise and workload is increasing, so is their influence. A very positive effect from INSPIRE is that all European NSDIs are - in terms of technology and implementation - on the same track. Interoperable cross-border network services will be available soon.

The National Mapping Agencies - likewise all other national authorities - have to make INSPIRE happen by providing the network services in conformance with the regulations. This will change the way they publish and distribute their data. It will certainly have an effect on their business models as well, although not explicitly required by the Directive.

Industry is not required to implement INSPIRE, because the laws only apply to the data owned and published by authorities. But industry will be effected from INSPIRE indirectly as the ESDI will ease the way to do international business. At least the vendors of software tools with networking capabilities benefit from INSPIRE already now. There is a growing business opportunity for transformation tools, web-based visualisation software, "INSPIRE-ready" servers and clients, etc.

Academic institutions contributed to INSPIRE in big EUfunded projects such as HUMBOLDT (HUMBOLDT Executive Board, 2011). There are still many areas for research left, e.g. ontologies and semantic transformation. From the reaction of 
users on the INSPIRE data specifications it is obvious that more efforts should be invested in the education on formal modelling, namely UML.

The typical European citizen uses Google Maps and Open Street Map. He/she will certainly not notice the introduction of an ESDI right from the start. It is with the cross-border data on themes such as flood risk, air pollution, postal addresses etc. that they may become users of INSPIRE services. Typically they will not access the services from the native source but via user-friendly applications and interfaces. Development and marketing of such applications is a task that will keep us busy when the ESDI is up and working.

\section{CONCLUSIONS}

INSPIRE is a big effort by the European Commission and the national governments. Its force comes from law, but its advantages are in technology. INSPIRE implements a service oriented architecture for spatial information, based on the principles established by ISO and OGC. INSPIRE takes advantage of these principles to create a European Spatial Data Infrastructure by connecting the National Spatial Data Infrastructures.

While the basic technology such as Web Map Services and Metadata Services will be implemented with no significant difficulties, it appears that achieving interoperability at the semantic level of data is less easy. INSPIRE promotes the approach of formal semantic modeling. The drafting teams face challenges in the development phase, and users complain on the complexity of the solutions. However, the approach is in line with international standards and innovative IT. It is hoped that industry and academic institutions help to bridge the remaining gaps between INSPIRE and users, by providing tools and education.

\section{REFERENCES}

De Groof, Hugo 2011. INSPIRE Evolution of the Environmental Acquis and Implementation in the Member States.http://inspire.jrc.ec.europa.eu/events/conferences/inspire_2011/presentations/plenaries/wed/0900_De_Groof_Pent_We ds.pdf (accessed 18 August 2011)

European Parliament and Council (Ed.), 2007. Directive 2007/2/EC of the European Parliament and Council of 14 March 2007 establishing an Infrastructure for Spatial Information in the European Community (INSPIRE). Official Journal of the European Union, L 108/1. http://eurlex.europa.eu/LexUriServ/L exUriServ.do?uri=OJ:L:2007:108:001:0014:EN:PDF (accessed 18 August 2011).

European Commission (Ed.), 2008. Commission Regulation (EC) No $1205 / 2008$ of 3 December 2008 implementing Directive 2007/2/EC of the European Parliament and of the Council as regards metadata http://eurlex.europa.eu/LexUriServ/LexUri-Serv.do?uri=OJ:L:2008:326:0012:0030:EN:PDF (accessed 18 August 2011).
European Commission (Ed.), 2009. Commission Regulation (EC) No 976/2009 of 19 October 2009 implementing Directive 2007/2/EC of the European Parliament and of the Council as regards the Network Services. http://eurlex.europa.eu/LexUriServ/LexUriServ.do?uri=OJ:L:2009:274:0009:0018:EN:PDF (accessed 18 August 2011).

European Commission (Ed.),2010a. Commission Regulation (EU) No 1089/2010 of 23 November 2010 implementing Directive 2007/2/EC of the European Parliament and of the Council as regards interoperability of spatial data sets and services. http://eurlex.europa.eu/LexUriServ/LexUriServ.do?ur-i=OJ:L:2010:323:0011:0102:EN:PDF (accessed 18 August 2011)

European Commission (Ed.), 2010b. Commission Regulation (EU) No $1088 / 2010$ of 23 November 2010 amending Regulation (EC) No 976/2009 as regards download services and transformation services. http://eurlex.europa.eu/LexUriServ/LexUriServ.do?uri=OJ:L:2010:323:0001:0010:EN:PDF (accessed 18 August 2011)

European Commission (Ed.), 2011a. Commission Regulation (EU) No 102/2011 of 4 February 2011 amending Regulation (EU) No 1089/2010 implementing Directive 2007/2/EC of the Euro-pean Parliament and of the Council as regards interoperability of spatial data sets and services. http://eurlex.europa.eu/LexUriServ/LexUriServ.do?uri=OJ:L:2011:031:0013:0034:EN:PDF (accessed 18 August 2011)

European Commission Joint Research Centre (Ed.), 2007. INSPIRE Network Services Architecture.http://inspire.jrc.ec.europa.eu/reports/ImplementingRules/network/D3.5_INSPIRE_N S_Architecture_v2.0.pdf (accessed 18 August 2011)

European Commission Joint Research Centre (Ed.), 2009. INSPIRE Metadata Implementing Rules: Technical Guidelines based on EN ISO 19115 and EN ISO 19119. http://inspire.jrc.ec.europa.eu/reports/ImplementingRules/metadata/MD_IR_an d_ISO_20090218.pdf (accessed 18.Aug.2011).

European Commission Joint Research Centre (Ed.), 2011a. INSPIRE Data Specifications for Annex I themes. http://inspire.jrc.ec.europa.eu/index.cfm/pageid/2 (accessed 18 August 2011)

European Commission Joint Research Centre (Ed.) 2011 b. INSPIRE Roadmap.: http://inspire.jrc.ec.europa.eu/index.cfm/pageid/44 (accessed 18 August 2011)

HUMBOLDT Executive Board (Ed.), 2011. Annual report 2010. http://www.esdi-humboldt.eu/files/1177-annual_report_2010tu-da-001-final.pdf (accessed 18 August 2011)

INSPIRE Drafting Team Data Specifications, 2010. INSPIRE Generic Conceptual Model. http://inspire.jrc.ec.europa.eu/documents/Data_Specifications/D2.5_v3_3.pdf (accessed 18 August 2011)

INSPIRE Thematic Working Group Land Cover, 2011. Data Specification on Land Cover - Draft Guidelines. http://inspire.jrc.ec.europa.eu/documents/Data_Specifications/INSPIRE_ DataSpecification_LC_v2.0.pdf (accessed 18 August 2011) 